\title{
KNOWLEDGE OF THE RISK FACTORS OF HEALTH STATUS AND TRENDS, THE POSSIBILITY OF PREVENTION
}

\author{
A. M. Ahmed*, N. Zhak \\ Department of Health Care, Medical Faculty, Trakia University, Stara Zagora, Bulgaria
}

\begin{abstract}
Health is a value of modern medicine person today is increasingly turning to face the common man, devote greater attention to issues related to the protection and enhancement of human health. This with increasing attention to human, with increasing respect for the person raising the place of the individual in society as a factor. (6) and great attention to the health of the individual. The health conditions of modern man need not be the object and subject of his health requires each individual new role which it is assigned by meaningful reconstruction of their thinking, mental construction and social life. Types of risk factors of health rational nutrition decreased physical activity smoking use of alcohol abuse drugs experiences.
\end{abstract}

Key words: Health risk factors enhancing value.

"Health is not just valuable for itself - it is a factor for growth. The very people in good health can give their full economic potential. "

\section{INTRODUCTION}

Health is a value of modern medicine personality today is increasingly turning to face the common man spends attention to problems related to the protection and enhancement of human health. This saprovezhda with increasing attention to human, increasing respect for human, with an increase in the place of the individual in society as a factor. (6) otuk and great attention to the health of the individual. The health conditions of modern man need not be the object and subject of his health requires each individual new role which puts him through meaningful reconstruction of their thinking, mental structure and social life.

Types of risk factors of health Irrational nutrition Reduced physical activity Smoking Use of alcohol abuse drugs psihotravmi experiences.

Particularly indicative of health and last but not least are the major diseases.

\footnotetext{
*Correspondence to: Atidje Mehmed Ahmed nurse, Department of Health Care, Tru-Medical School, Stara Zagora, ati1994@abv.bg
}

Cardiovascular diseases, malignant new formations, chronic respiratory diseases, traumatic injuries, diabetes and mental disorders. (1)

Food is the only and indispensable source for living organisms to obtain the necessary lifecycle energy and plastic materials to build their tissues and organs. This is true for people.

Rational and balanced nutrition is one of the main factors of good health, normal physical and mental development, employability and active longevity

Cardiovascular risk factor

Vascular diseases malignant diseases-our-our chronic lung diseases Diabetes mellitus Cirrhosis fits-muscle ache tubs neuron-tech disorders

\section{Smoking AlcoholNutritionLack of physical activityObesityExternal factorsHereditary disease}

Food can be as a source of health and cause disease or worsening of an existing one. (6) To be a source of health nutrition must meet certain iziskvaniya.Da contains optimal ratio basic food sub- stances Protein: Fat: Carbohydrates 1: 1: 4; 


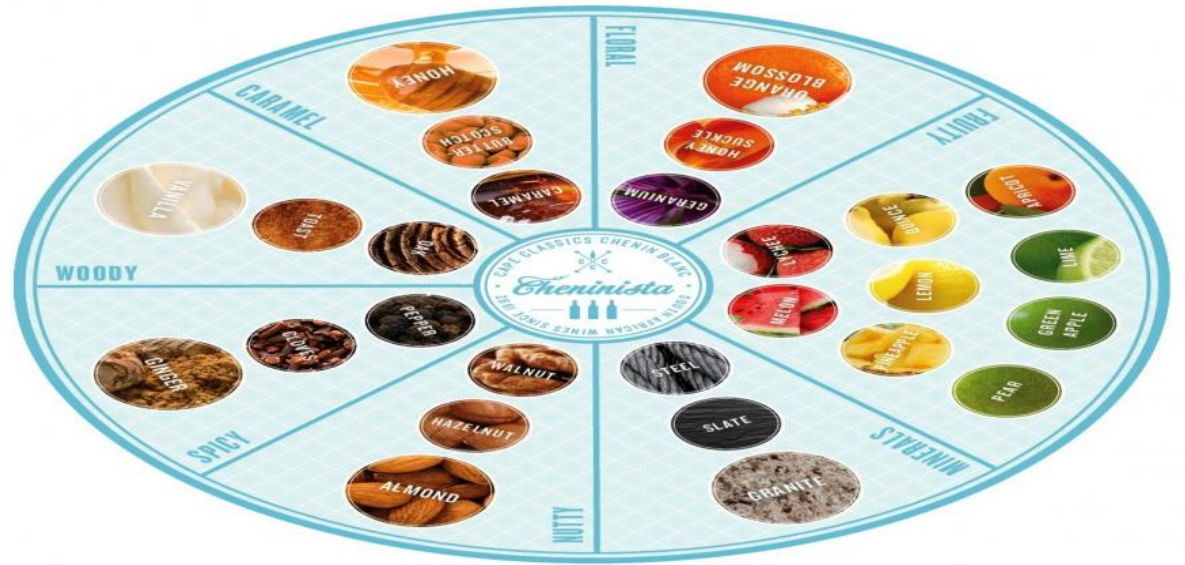

Irrational nutrition is feeding which in sebesi suggests that essential nutrients tribute accepted within certain limits so that the human body is affected by this imbalance and nesaotnoshenie correct this imbalance and improper nutrition forged products not content just $60 \%$ of people toggling attention to what they put in the dish is called irrational hranene.Tendentsiite for Bulgaria are the following: According to a study by the World Health Organization, Bulgarians most often suffer from diseases associated with poor nutrition and unhealthy. Our country is a leader in cardiovascular disease $66 \%$ of the population suffers from hypertension, the cause of which is the consumption of fatty and salty canned foods. (1) Reasons for the majority of oncological diseases also may be heavy and canned foods and the lack of fruits and vegetables in the daily menu. Of them suffer $17 \%$ of the population. The undisputed fact about the emergence and progress of diabetes is the importance of the food we eat. Irrational nutrition and overeating are prerequisites for development of the disease suffered by $2 \%$ of Bulgaria horata.V men suffering from overweight and even overweight are $63 \%$ and women - 53\% .Vliyanie physical activity on the human body and health: May Probably the most universal factor affecting all the systems of the human body's physical activity. Physical activity includes any activity in which we use our muscle strength to perform movement. Depending on its intensity, and orderliness are observed to a lesser or greater extent, changes in all organs and systems. (6) In consequence, our muscles work, including cardiovascular and respiratory system to supply oxygen and nutrients. So under the influence of systemic physical activity cardiorespiratory depression become more efficient and more economical. The metabolism is altered, increasing the power consumption, thereby maintaining normal body weight. Systematic physical activity improves muscle strength, bone strength and tendons. People with high physical activity are more alert, better selfesteem and suffer less from depression. One of the main causes of major diseases has reduced physical activity of modern man. (3) Positive effects of systemic physical activity on the body stimulates growth and bone strength increases skeletal muscle mass improves kravourosyavaneto heart, increasing its capillary network increases heart mass and stroke volume is reduced pulse rate and blood pressure increases the vital lung capacity to stimulate hematopoiesis (blood formation) improves blood supply to the brain improves the perception, thinking, memory and attention improves mental performance, mood and selfesteem intensifying its exchange protsesi.Uvelichava is the level of good cholesterol (HDL) - the expense of bad (LDL) reduces the deposition of fat is increased immunity. (2) The trends for decreased physical activity - sedentary lifestyle and contributes to the formation of blockages in the arteries, which in turn lead to vascular problems such aterosklerozata.- reduced activity increases the risk of developing certain types of cancer, such as breast cancer, colon cancer and other malignancies tumori.reduced physical activity decreased muscle strength, affects the joints and their normal functioning and thus predisposes the organism to diseases such as arthritis and osteoporosis, in which bones become porous and chuplivi.When people leading a sedentary lifestyle reduces brain activity and this is reflected in the reactions of everyday life. If the brain is not loaded enough, it can lead to depresiya.People who lead a sedentary lifestyle of small, develop high blood pressure at an early vazrast.- Such people do not like to socialize much and prefer to stay at home glued on the couch. They hardly hesitate to adopt a life's challenge.

\section{Smoking as a risk factor}

Smoking is inhalation (typically orally) of the smoke of smoldering tobacco leaves, by adopting the nicotine. People smoking practitioners are called "smokers". Excessive 
MEHMED AHMED A., et al.

smoking leads to nicotine addiction and habituation resulted in marked alteration of the internal organs. The most commonly affected organs associated with respiration, cardiovascular system, digestion and dr.Vanshni negative consequences can be: yellow teeth and mustache, disagreeable breath, unpleasant taste, blunt mirisu sensation, dry facial skin, yellowing of the fingers and hands, insomnia and others.

Trends for smoking in Bulgaria -

The trend among young people smoking is increasing

No smoking in Bulgaria with the Health Act basically prohibited smoking in enclosed public places, such exceptions are regulated in the Ordinance on the terms and conditions under which the exceptionally smoking in separate areas of indoor public places and indoor workplaces, adopted Council of Ministers with Decree № 329 (January 2005). (4)

Psihotravmi experiences as a health risk factor Clinical neurological symptoms:

Headache - can say that is a major neurotic symptom most often occurs. Patients describe it as an astringent whole head, especially in the upper part, as imposed cap (Shark called it "the helmet of neurasthenic").

"This" neurasthenic helmet "is explained by the lowered threshold of excitability reception coming from the soft tissues of the skull roof, normally unconscious."

Violation in the sleep cycle - here are observed following varieties Difficulty sleeping sleeping patient expected, and that it slows down more and adjourned. Often the initial symptom of neurotic illness.

Shallow sleep - patients with a constant feeling of being in somnolence, dreaming nightmares. Interrupted sleep - characteristic is repeatedly waking and sleep at night. (4)

Authorities manifestations of neurosis - chest pain, palpitations, a feeling of heart attacks in the head (cardiovascular symptoms can somatizira, as an initial stage of hypertensive disease), spasms in the throat (fear of cancer), dystonia-vegetative syndrome (sweating, pricking the skin, redness and facial pallor, tremor of the extremities), back pain, stomach cramps, distal paraesthesia very fear of paralysis kraynitsite.Alkoholna and drug abuse as a risk factor

Alcohol abuse is the presence of dangerous and unhealthy habits of drinking, such as drinking every night or periodically rewrite. Alcohol dependence or alcoholism means physical or mental addiction to alcohol. Flow and distribution:

Alcohol abuse can lead to accidents, violence, social exclusion, problems at work, family or school. Alcoholism is a continuous, chronic condition. Alcoholics often have other mental problems such as depression or anxiety disorders, such as drinking aggravates their symptoms. Phobias occur 10 times more frequently in alcoholics. In pregnant women can harm the fetus. The complications of alcoholism include cirrhosis, pancreatitis, hypertension, stroke, osteoporosis, impotence, cancer. In the US, 12-14 million adults abuse alcohol as men are 2-5 times more than women. Drug use is like playing with fire: there's always risks. Among the risks is the danger of physical or psychological zavisimost.Pri use of certain substances there is a risk of overdosing or consumption in lethal quantity. Some users deliberately take a higher dose. Most often what happens is that it is consumed something different from what the user expects that adopted. These are the cases when a pill or powder does not contain what the seller has declared. For illegal drugs, there is no quality control. Users can also simultaneously take other drugs with effects that are often unpredictable and sometimes lethal. (5) Drugs affect the perception of reality and the ability of the user to concentrate. In city traffic or work drug may increase the possibility of accidents. Drug use while driving is punishable by law. As a result of drug use can hurt performance at school and work.

Trends in Bulgaria alcoholism and narcotic stop

drug use is strictly prohibited by legal but the use of certain alcoholic drinks are freely marketed freely and can be p\$urchased worst is when you overdose percent and so far is extremely high with a tendency to grow studies are the most vulnerable young population teenagers and provided with the following diagnosis alcoholism treatment has the following has a plurality of individual drugs for the treatment of alcoholism. Individual drugs are designed to help reduce or stop the use of alcohol as a whole. Other treatments include cognitive therapy techniques include motivational therapies to group therapies. European Drug Report 2014. "Trends and Developments" once again describes the overall stable situation, which is characterized by some positive signs with regard to traditional types of drugs. Meanwhile EMCDDA warns shaping the new threats posed by synthetic drugs, including stimulants, new psychoactive substances and medicinal products which occupy an increasingly 
important place of the changing drug market in Europe. (5)

\section{Purpose}

This study aims to establish cultural knowledge of the population of men and women and teenagers with special attention they know the risk factors for unhealthy lifestyles and risk factors affecting the health of human and morbidity rates due to exposure to harmful factors and their impact necessary preventive measures.

\section{MATERIALS AND METHODS}

The study was conducted in the period January-February 2015. The study used the following methods:

a) Documentary method analysis of documents (programs for prevention of unhealthy lifestyle here.

B) Sociological method - held a direct anonymous poll among 45 women and 40 men from the cities of Stara Zagora Velingrad and their regions.

\section{RESULTS AND DISCUSSION}

For the purposes of the study were interviewed 45zheni aged 20 to 65 years of age and 40 men from 20 to 45 years of age, research shows that people leading sedentary lifestyles are aging faster. This is due to the damage of their telomeres formations located at the end portions of chromosomes. Telomeres play an important role in the prevention of accelerated stareene.Po less than half of the respondents indicated that they know the risk factors for healthy lifestyles result is unsatisfactory because considering the fact that continuous and varying degrees are exposed to the harmful effects of a number of factors must focus efforts and resources to promote data for possible damages and public education for recognizing the connection between risk factors and their zdrave.Neobhodimo was to discover factors that respondents are exposed revealed that 25.90 percent of women are exposed to smoking as a risk factor and reduced physical activity with a sedentary lifestyle.

\section{CONCLUSIONS}

The test could be drawn the following conclusions:

1Difference in awareness of risk factors observed in the education level and place of residence of the respondents.

2.wowman with low educational attainment mainly not know the risk factors related to healthy lifestyle.

3.Purpose $5 / 6$ of the respondents that would necessarily change their lifestyle if they know that this will prevent them from reducing morbidity.

4.that dominates the positive response was no difference in the attitudes of women and men as women from villages in a high percentage are reluctant to change their way of life.

5is to create a training program to find a place and nurse its rolya.Edna roles in these programs could be implemented through training and informing the population about the types of risk factors threatening a healthy lifestyle.

Conclusion The report finds maintaining overall downward trend in deaths related to drug use, although it remains one of the main causes of death among young people in the EU. Control of specific factors changing healthy lifestyle and effective integrated prevention of non-communicable diseases which promotes healthy eating and physical activity control alcohol consumption overweight and obesity.

\section{REFERENCES}

1. Achkova, M.Prilozhna psychology in medicine and health care. S., 2001.

2. Petkova, D.Sastoyaniya between life and death

3. Ivanov In "Development in a healthy life" .Sofiya 2004

4. http://infocall.bg/galina-dojchinova17481/uslugi/lechenie-na-alkoholna-inartokichna-zavisimost-sofiia-2364.html

5. http://www.zdrave.bg/?c=n\&id=5019

6. http://www.medihelp.bg/mediacenter/press- $\%$ 8F\% D1\% 